\title{
ALGORITHMS FOR CLINICAL ASSESSMENT OF THE CERVICAL SPINE IN PATIENTS WITH SEVERE TRAUMA: A MIXED-METHOD ANALYZIS
}

\author{
ALGORITMOS DE AVALIAČÃO CLÍNICA DA COLUNA CERVICAL EM PACIENTES COM \\ TRAUMATISMO GRAVE: UMA ANÁLISE MISTA
}

\section{ALGORITMOS DE EVALUACIÓN CLÍNICA DE LA COLUMNA CERVICAL EN PACIENTES CON TRAUMATISMO GRAVE: UN ANÁLISIS MIXTO}

\author{
Felpe leonardo 1 , Gabriel Franco de Camargo Galindo', Otavio Soriano Teruel Pagamisse', José Mauro da Silva Rodrigues ${ }^{2}$ \\ 1. Pontifícia Universidade Católica de São Paulo (PUC-SP), Faculdade de Ciências Médicas e da Saúde (FCMS), São Paulo, SP, Brazil. \\ 2. Pontifícia Universidade Católica de São Paulo (PUC-SP), Faculdade de Ciências Médicas e da Saúde (FCMS), Department of Surgery, São Paulo, SP, Brazil.
}

\begin{abstract}
Objective: Cervical trauma is an important cause of morbidity and mortality, affecting $2 \%$ of patients admitted to emergency units. Therefore, this study aims to compare the use of two clinical cervical spine evaluation algorithms, the Canadian C-Spine Rule (CCR) and the National Emergency X-radiography Utilization Study (NEXUS). Methods: A descriptive study of the use of the two algorithms by medical residents in the initial assessment of severely traumatized patients admitted to the regional emergency unit was conducted. The evaluation of the indication for imaging tests and the positive predictive value of the algorithms were the parameters analyzed. Finally, the residents answered a questionnaire evaluating the applicability, degree of confidence and advantages of both flowcharts. Results: There was no significant difference between the number of indications for imaging or their predictive values. In the analysis of the questionnaires, the CCR proved to be more reliable and the NEXUS more applicable, and the positive and negative points of applying each of them were highlighted. Conclusion: It is concluded that the two methods are similar in detecting injuries and optimizing the use of imaging exams, being equally indicated to evaluate cervical trauma. However, the technical specifics of each must be taken into account when deciding which to use. Level of evidence IV; Descriptive Study.
\end{abstract}

Keywords: Emergencies; Wounds, Nonpenetrating; Spinal Injuries; Algorithms.

\section{RESUMO}

Objetivo: O trauma cervical é uma importante causa de morbidade e mortalidade, com acometimento de $2 \%$ dos pacientes admitidos nas unidades de emergência. Assim sendo, a pesquisa visa comparar a utilização de dois algoritmos clínicos de avaliação da coluna cervical: Canadian C-Spine Rule (CCR) e National Emergency X-radiography Utilization Study (NEXUS). Métodos: Foi realizado um estudo descritivo da utilização dos dois algoritmos por médicos residentes na avaliação inicial de pacientes traumatizados graves admitidos na unidade de emergência regional. A avaliação da indicação de exames de imagem e do valor preditivo positivo dos algoritmos foram os parâmetros analisados. Por fim, os residentes responderam a um questionário de avaliação da aplicabilidade, grau de confiança e vantagens de ambos os fluxogramas. Resultados: Não houve diferença significativa entre os números de indicação para imagem nem dos valores preditivos. Na análise do questionário, o CCR mostrou-se mais confiável e o NEXUS foi mais aplicável, sendo destacados os pontos positivos e negativos da aplicação de cada um deles. Conclusões: Conclui-se que houve semelhança na detecção de lesões e otimização da utilização de exames de imagem entre os dois métodos, sendo igualmente indicados para avaliação de traumatismo cenvical, contudo cada um tem especificidades técnicas que devem ser levadas em conta no momento da escolha. Nível de evidência IV; Estudo descritivo.

Descritores: Emergências; Ferimentos não Penetrantes; Traumatismos da Coluna Vertebral; Algoritmos.

\section{RESUMEN}

Objetivo: El trauma cervical es una importante causa de morbilidad y mortalidad, con acometimiento de $2 \%$ de los pacientes admitidos en las unidades de emergencia. Siendo así, la investigación tiene como objetivo comparar el uso de dos algoritmos clínicos de evaluación de la columna cenvical: Canadian C-Spine Rule (CCR) y National Emergency X-radiography Utilization Study (NEXUS). Métodos: Fue realizado un estudio descriptivo del uso de los dos algoritmos por médicos residentes en la evaluación inicial de los pacientes traumatizados graves admitidos en la unidad de emergencia regional. La evaluación de la indicación de exámenes de imagen y del valor predictivo positivo de los algoritmos fueron los parámetros analizados. Finalmente, los residentes respondieron un cuestionario de evaluación de la aplicabilidad, grado de confianza y ventajas de ambos diagramas de flujo. Resultados: No hubo diferencia significativa entre los números de indicación para imagen ni de los valores predictivos. En el análisis del cuestionario, el CCR se mostró más confiable y el NEXUS fue más aplicable, siendo destacados los puntos positivos y negativos de la aplicación de cada uno de ellos. Conclusiones: Se concluye que hubo semejanza en la detección de lesiones y optimización del uso de exámenes de imagen entre los dos métodos, siendo igualmente indicados para la evaluación de traumatismo cenvical, aunque cada uno tiene especificidades técnicas que deben ser llevadas en cuenta en el momento de elegir. Nivel de evidencia IV; Estudio descriptivo.

Descriptores: Urgencias Médicas; Heridas no Penetrantes; Traumatismos Vertebrales; Algoritmos. 


\section{INTRODUCTION}

The standardization of the care of patients who are victims of severe traumatic injury has been well-established since 1980, when the first edition of Advanced Trauma Life Support (ATLS) came out. This course aims to organize such care, prioritizing the evaluation and early treatment of the greatest threats to life. Within its care protocol, placement of the cervical collar is the first step in the prehospital care approach to these patients, justified by the prevention of secondary injuries to this vertebral segment that can occur during transport to the treatment location. ${ }^{1}$

Vertebral traumatism is an important cause of death or disability in severely traumatized patients and is present in approximately $6 \%$ of these patients, with 55\% of these injuries to the cervical spine, representing $2 \%$ of total traumas. ${ }^{2,3}$ Injuries of the higher levels can affect the functioning of the brain stem, impairing vital functions and injuries of the lower levels can lead to motor deficit in the lower limbs and even to quadriplegia. For this reason, up until the previous version of the ATLS, imaging examinations of the cervical spine, either by radiography or computed tomography (CT), were among the mandatory tests to be performed on admission to the treatment site. ${ }^{1,4}$

However, American data from 2009 showed that of the one million patients transported to the emergency room with suspected cervical trauma that year, only $2 \%$ had some kind of fracture and less than $1 \%$ developed neurological or motor deficits. ${ }^{3}$ In addition to these epidemiological data, two other factors that corroborate this clinical screening process are less exposure to radiation and lower cost. Computed tomography (CT), the gold standard for diagnosis of traumatic cervical injuries, brings with it these two characteristics even more intensely than simple radiography, a method previously used widely because it was more available. It contains a higher dose of radiation and a higher cost, which makes screening via clinical algorithms a less harmful and more cost-effective option, especially when the underfunded national health scenario is analyzed. ${ }^{5,6}$ All these factors taken together evoked discussion about the mandatory status of the imaging examination of this segment, which ended up being removed from the most recent version of the ATLS and replaced by the criterion of executing two clinical screening algorithms. ${ }^{1}$

A clinical algorithm can be generically defined as "a clinical tool that quantifies the individual contribution of various components of the clinical history, physical examination and/or laboratory examinations in a patient's diagnosis, prognosis or response to treatment". ${ }^{7}$

The well-established algorithms that assist the physician in the decision to discontinue the cervical collar or evaluate it by imaging methods are the Canadian C-spine Rule (CCR) and the National Emergency X-Radiography Utilization Study (NEXUS).

The CCR is indicated for stable and alert victims of trauma with a Glasgow coma scale (GCS) score of 15, where cervical injury is suspected. It consists of three steps. The first is to eliminate any high-risk factors for cervical trauma (age over 65 years old, dangerous trauma mechanism and/or paresthesia in the extremities), then eliminate lower risk factors and, finally, assess the patient's ability to actively rotate the neck. The absence of any risk factors and the ability to rotate the neck indicate that image evaluation of the cervical spine is not necessary, and the collar can be discontinued (Chart 1). ${ }^{1}$

NEXUS is also indicated for severely traumatized patients with suspected cervical injury. It consists of five criteria (tenderness in the midline of the cervical spine, evidence of intoxication, low level of consciousness represented by GCS $<15$, focal neurological deficit and distracting painful injuries). Only the absence of all of them allows the cervical collar to be discontinued and the presence of any one of them is an indication for image evaluation (Chart 2)., ${ }^{1,8}$

When submitted to validation, both produced excellent results, CCR and NEXUS having sensitivity of $99 \%$ and $100 \%$ and specificity of $42.5 \%$ and $12.9 \%$, respectively. ${ }^{9,10}$ Even with a small difference in the sensitivity and specificity values, both are highly effective in predicting the risk of cervical injuries and are widely used in medical practice worldwide.
Chart 1. Canadian C-spine Rule (CCR)

\begin{tabular}{l} 
1. Any high-risk factors that require radiographic examination? \\
- Age $\geq 65$ years \\
- Dangerous trauma mechanism (automobile vs. pedestrian; rollover/ \\
ejection; fall $>1$ meter) \\
- Paresthesia in the extremities \\
\hline 2. Any low-risk factor that allows a safe assessment of range of motion? \\
- Simple rear-end vehicle collision \\
- Seated or walking position \\
- Late onset neck pain \\
- Absence of feeling in the midline of the cervical spine \\
\hline 3. Unable to actively rotate the neck $\left(45^{\circ}\right.$ to the right and left)? \\
An affirmative answer to any of the criteria indicates imaging of the cervical \\
spine. \\
Source: Advanced Trauma Life Support (10th Ed.) $)^{1}$ - adapted.
\end{tabular}

Chart 2. National Emergency X-Radiography Utilization Study (NEXUS).

\begin{tabular}{|l|}
\hline - Tenderness in the midline of the cervical spine \\
\hline - Evidence of intoxication \\
\hline - GCS $<15$ \\
\hline - Focal neurological deficit \\
\hline - Distracting painful injuries \\
\hline An affirmative answer to any of the criteria indicates imaging of the \\
cervical spine.
\end{tabular}

Source: Advanced Trauma Life Support (10th Ed.) - adapted.

A third variable can also be used in the comparison - reduction in the number of imaging examinations required for cervical evaluation after its application. ${ }^{9,11}$ An initial study in a Canadian emergency center reported a reduction of $12.9 \%$ in the number of radiographs when compared to pre-CCR implementation numbers. ${ }^{9}$ Another Canadian study was able to compare the radiography rate between the two algorithms, showing a lower value for CCR (55.9\%) than for NEXUS (66.6\%). ${ }^{12}$

Although accurate, such algorithms can only guarantee a benefit if they provide the same quality of patient care, less time spent by physicians and reduced costs to the system, and this depends on characteristics intrinsic to them more than on the accuracy that they offer. Otherwise, using them becomes an obstacle. ${ }^{13}$

Due to the heavy use of the ATLS recommendation in the Regional Emergency Unit of the Conjunto Hospitalar de Sorocaba/ SP (URE-CHS), both algorithms are widely used. This study aims for a mixed evaluation of these algorithms, verifying their positive predictive value, i. e. their ability to identify true positives among the results indicated as positive, their efficiency in reducing the number of cervical spine imaging examinations following severe trauma, and the evaluation of the physicians in the service who use it in terms of applicability and reliability. The objective of this analysis is to certify whether one is superior to the other, as used in this regional emergency unit in the state of São Paulo, Brazil.

\section{METHODS}

\section{First part: determination of the values for the indication of an imaging examination}

A descriptive study was conducted using the algorithms in victims of blunt trauma wearing a cervical collar who were admitted to the URE-CHS during the period from August 2019 to April 2020. The two protocols were already routine and equally applied, being left up to the attendant to choose between them. In the secondary initial trauma care evaluation, the resident physician uses one of them, CCR or NEXUS, left available in the emergency room for checking the criteria for each patient, and notes the results in the specified field for future analysis of the conducts. The Informed Consent Form (ICF) was applied to everyone who agreed to participate in the study, after approval of the project by the Institutional Review Board of the Faculdade de Ciências Médicas e da Saúde of the Pontifícia Universidade Católica de São Paulo as opinion no. 3.757.164 (CAAE: 
10498119.7.0000.5373). The results were organized into tables and submitted to statistical analysis of the proportional distribution of the data, using the Chi-squared test to compare the number of radiographic examination indications between the two methods.

\section{Second part: determination of the positive predictive value of the algorithms}

This part of the study was conducted in the same way as the previous part. The filled-out protocol form was added to the evaluation of the results of the patient's cervical spine imaging examination, when indicated. This phase took place during the period from January to April 2020. The difference from the previous step was that, in the case of referral for image examination, the patient's identification number was recorded for future analysis of the tomography reports in order to verify the existence or not of traumatic cervical injuries, data necessary for the calculation of the positive predictive value (PPV) of the algorithm test. This was done without using any other personal patient information contained in their medical records, which were not accessed. The results were organized in tables and submitted to statistical evaluation of the proportional distribution of the data, using Fisher's exact test to compare the number of indications of radiography between the methods, since frequencies less than five were found.

\section{Third part: qualitative analysis of the applicability and reliability of the algorithms}

Finally, a virtual questionnaire was administered to all the resident physicians who participated in the study, seeking to assess quantitatively (on a scale of zero to ten) the applicability (ease of remembering and executing the algorithm in an emergency scenario) and the degree of confidence (safety of performing the conduct that they indicated) and qualitatively the positive and negative points of each algorithm. Finally, they were asked to choose which of the two methods they preferred to work with. The results were organized into tables and submitted for quantitative statistical evaluation of the proportional distribution of the data using the Student's t test and qualitative evaluation of the open questions using content analysis, as recommended by Bardin. ${ }^{14}$

\section{RESULTS}

\section{Emergency room protocol data}

To determine the imaging examination indication values, 250 protocol usage forms were verified $(n=250)$. Of these, $120(48 \%)$ were samples of the CCR algorithm and 130 (52\%) of the NEXUS algorithm. Sixty-six (55\%) of the protocols performed using the CCR algorithm indicated removal of the cervical collar and 54 (45\%) indicated the need for an imaging examination. Seventy-eight (60\%) of those performed using the NEXUS algorithm indicated cervical collar removal and 52 (40\%) indicated the need for an imaging examination. These data are presented in the following table. (Table 1)

The hypothesis test (Chi-squared) produced a value of $p=0.424$, with no significant difference between the proportions analyzed, which shows that the methods are equally effective in reducing the number of imaging examinations.

To determine the PPV, 76 extended protocols were applied. Of these, $33(43.4 \%)$ indicated an imaging examination, $20(60.6 \%)$ of which were samples of the CCR algorithm and $13(39.4 \%)$ of the NEXUS algorithm. The cervical spine CTs performed showed that only 2 indications from the CCR algorithm and 3 from the NEXUS algorithm were truly altered, $\mathrm{PPV}=10 \%$ and $\mathrm{PPV}=23 \%$, respectively. (Table 2)

The traumatic injuries revealed were vertebral body fracture (simple and with deviation), transverse process fracture, spinous process fracture, arthrolisthesis and transection of the spinal canal.

The hypothesis test (Fisher's exact test) resulted in a value of $p=0.315$, demonstrating no significant difference between the values analyzed, which shows that there is no relevant significant difference between the positive predictive powers of the two methods.
Table 1. Description of the sample in terms of indications for imaging examination

\begin{tabular}{c|c|c|c}
\hline $\begin{array}{c}\text { Conduct/Algorithm } \\
\text { \% horizontal } \\
\text { \% vertical }\end{array}$ & CCR & NEXUS & Total \\
\hline \multirow{3}{*}{ Remove collar } & 66 & 78 & 144 \\
\cline { 2 - 4 } & 45.83 & 54.17 & 100.0 \\
\cline { 2 - 4 } & 55.00 & 60.00 & 57.60 \\
\hline \multirow{3}{*}{ Image } & 54 & 52 & 106 \\
\cline { 2 - 4 } & 50.94 & 49.06 & 100.0 \\
\cline { 2 - 4 } & 45.00 & 40.00 & 42.40 \\
\hline \multirow{2}{*}{ Total } & 120 & 130 & 250 \\
\cline { 2 - 4 } & 48.00 & 52.00 & 100.0 \\
\cline { 2 - 4 } & 100.0 & 100.0 & 100.0 \\
\hline
\end{tabular}

Table 2. Description of the samples in terms of PPV

\begin{tabular}{c|c|c|c}
\hline $\begin{array}{c}\text { Conduct/Algorithm } \\
\text { \% horizontal } \\
\text { \% vertical }\end{array}$ & CCR & NEXUS & Total \\
\hline \multirow{3}{*}{ Normal } & 18 & 10 & 28 \\
\cline { 2 - 4 } & 64.29 & 35.71 & 100.0 \\
\cline { 2 - 4 } & 64.29 & 76.92 & 84.85 \\
\hline \multirow{3}{*}{ Altered } & 2 & 3 & 5 \\
\cline { 2 - 4 } & 40.00 & 60.00 & 100.0 \\
\cline { 2 - 4 } & 10.00 & 23.08 & 15.15 \\
\hline \multirow{2}{*}{ Total } & 20 & 13 & 33 \\
\cline { 2 - 4 } & 60.60 & 39.40 & 100.0 \\
\cline { 2 - 4 } & 100.0 & 100.0 & 100.0 \\
\hline \multirow{2}{*}{} & & &
\end{tabular}

\section{Resident physician questionnaire data}

The questionnaire was answered by 13 residents physicians who participated in the research $(n=13)$. As for the degree of confidence of each of the methods, CCR had a mean score of $9.15 \pm 0.68$ and NEXUS had a mean score of $7.77 \pm 0.59$ points. The hypothesis test resulted in a value of $p<0.001$, revealing that the CCR algorithm was statistically more reliable than NEXUS. Regarding the applicability of each method, CCR had a mean score of $6.85 \pm 1.21$ and NEXUS had a mean score of $9 \pm 0.81$. The hypothesis test resulted in a value of $p<0.001$, revealing that the NEXUS algorithm was statistically more applicable than CCR.

Analysis of the qualitative content of the CCR algorithm confirmed its positive points (the number of repetitions in parentheses) as follows: breadth of scope (4), consideration of the mechanism of trauma (3), high sensitivity (3), safety (2), and clarity/objectivity (1). The negative points reported were difficult to memorize (5), takes time to execute (4), low specificity (2) and complexity (1).

Analysis of the qualitative content of the NEXUS algorithm confirmed its positive points as follows: simplicity (4), easy to execute (3), easy to memorize (3), practicality (3) and speed of execution (3). The negative points reported were low sensitivity (4), no consideration of the mechanism of trauma (2) and no consideration of age (2).

Finally, when asked which algorithm they preferred to use in practice, 10 responded that they preferred NEXUS (76.9\%) and 3 that they preferred CCR (23.1\%). These results are shown in Table 3.

\section{DISCUSSION}

The first data resulting from this study refers to the value of the imaging indication for the CCR and NEXUS protocol analysis, being $45 \%$ and $40 \%$, respectively, with no significant difference between them. This comparison between CCR and NEXUS has already been made by Stiell et al., revealing values of $55.9 \%$ and $66.6 \%$, and by Ala et al. in 2017 , revealing values of $57.5 \%$ and $47.5 \%$, respectively. ${ }^{12,15}$ These researchers used the same methodology in their studies, the first having a significantly larger sample and an outcome that differs from the one found here, which is closer to that of the 
Table 3. Description of the results obtained from the questionnaire.

\begin{tabular}{|c|c|c|c|}
\hline Question analyzed & CCR & NEXUS & p \\
\hline $\begin{array}{l}\text { Degree of } \\
\text { confidence }\end{array}$ & 9.15 & 7.77 & $<0.001$ \\
\hline Applicability & 6.85 & 9.0 & $<0.001$ \\
\hline \multirow{5}{*}{ Positive points } & Breadth of scope & Easy to execute & \\
\hline & $\begin{array}{c}\text { Consideration of } \\
\text { mechanism of trauma }\end{array}$ & Easy to memorize & \\
\hline & High sensitivity & Practicality & \\
\hline & Safety & Speed of execution & \\
\hline & Clarity/objectivity & & \\
\hline \multirow{4}{*}{ Negative points } & Difficult to memorize & Low sensitivity & \\
\hline & Takes time to execute & $\begin{array}{c}\begin{array}{c}\text { No consideration of } \\
\text { age }\end{array} \\
\end{array}$ & \\
\hline & Low specificity & $\begin{array}{l}\text { No consideration of the } \\
\text { mechanism of trauma }\end{array}$ & \\
\hline & Complexity & & \\
\hline $\begin{array}{c}\text { How many prefer to } \\
\text { use it }\end{array}$ & $3(23.1 \%)$ & $10(76.9 \%)$ & \\
\hline
\end{tabular}

second study. Such concordance may be related to the sample size and the epidemiological characteristics of the trauma mechanism, which are similar to those of this study.

Studies of standalone protocols were also able to demonstrate their ability to reduce imaging examination indications when compared to non-systematic clinical judgements. A randomized controlled clinical trial conducted by Stiell et al., demonstrated a $12.8 \%$ reduction in cervical imaging examination in severe traumatisms using the CCR, a fact also evidenced by an Australian non-randomized, before-and-after clinical trial. ${ }^{11,16}$ As for NEXUS, a retrospective observational study conducted by Griffith et al. that compared the clinical versus radiological database information of trauma victims found that $23.9 \%$ of the images were taken unnecessarily for not using this protocol. ${ }^{17}$ However, another study conducted by Dearden and Hughes reported no difference between the use of the NEXUS algorithm and non-systemic clinical evaluation in an emergency service, which can be justified by clinical judgement trained according to ATLS recommendations. ${ }^{18}$ In this study, retrospective intervention data were not collected to confirm whether or not there was an effective reduction in the number of imaging tests.

The second result of this research is the positive predictive value of each algorithm, $10 \%$ and $23 \%$ for CCR and NEXUS, respectively. These values are well above those found in the literature, which range from $3 \%$ to $6.03 \%$ for the CCR and from $2.7 \%$ to $9.1 \%$ for NEXUS, but they still reflect the relative superiority of NEXUS in predicting a positive imaging examination result. 9,19,20 The prospective cohort studies conducted by Duane et al., discuss which of the variables included in these algorithms can be considered good individual predictors of a fracture when analyzed under the lens of the gold standard for these cases, cervical spine CT, in order to formulate a new algorithm derived from them with greater specificity without losing sensitivity. The significant factors in this predictive model were tenderness in the midline of the cervical spine and GCS $<15$ (common to both algorithms), age equal to or greater than 65 years, paresthesia, rollover/ejection from the vehicle and not being able to assume the sitting position (present only in the CCR). ${ }^{19,20}$ Even with a greater number of predictive factors, the CCR was not superior in terms of the PPV due to the large number of clinical criteria with low predictive power that it also includes, which reduces its specificity. An evaluation of each individual criterion was not performed in the present study.

A third variable that could interfere with algorithm use is interobserver variability, which can be defined as the ability to reproduce the same result when applied by two different observers. ${ }^{21}$ However, when analyzed, both CCR and NEXUS have a $k$ value considered to reflect good concordance, estimated at 0.75 and 0.73 , respectively. ${ }^{22,23}$

When we analyzed the subjective assessment made by the resident physicians in this study on algorithms, we noticed a clear preference for using NEXUS (76.9\% vs. $23.1 \%)$, which can be explained by its being easier to apply, despite the lower confidence they have in it.

The most reliable method from the residents' point of view was the CCR (9.15\% vs. $7.77 \%)$. Seeking to infer something from this variable, a study checked how many times the CCR and NEXUS protocol indications for each examination were respected by those who applied it, estimating a reliability of $91.2 \%$ and $96.8 \%$, respectively, ${ }^{24}$ showing the opposite of the data found here, possibly due to the measurement technique used. Two other Canadian studies that evaluated only the CCR protocol when used by nurses found reported reliability of $95.2 \%$ and $98.7 \%$ in two different years. ${ }^{25,26}$

Objectively, the degree of confidence is relatively associated with the sensitivity of the test, which is close to $100 \%$ for both tests. However, some variables absent in NEXUS may be responsible for decreasing the degree of confidence in its indications, namely, no consideration of the mechanism of trauma and no consideration of the patient's age, both factors with high predictive value. ${ }^{19}$

NEXUS was considered to be the most easily applicable algorithm (9\% vs. $6.85 \%$ ). The factors encountered in the open responses that support this prevalence are its speed, practicality, and ease of memorization as compared to the other. A study conducted with emergency service physicians in the USA showed that $56 \%$ use NEXUS more than $75 \%$ of the time versus $10 \%$ who use CCR in this same proportion. When each of these groups was questioned about memorization of the algorithm, $62 \%$ of those who preferred NEXUS remembered it completely, as opposed to only $33 \%$ of those who preferred CCR. ${ }^{27}$

\section{CONCLUSION}

Epidemiological, clinical and economic factors led to the removal of the ATLS requirement to perform imaging examinations for all seriously injured patients before removing the cervical collar, replacing it with clinical screening. The two suggested validated algorithms, the Canadian C-spine Rule (CCR) and the National Emergency X-Radiography Utilization Study (NEXUS), are widely used due to their safety.

Through the data of this study it was possible to verify that there is no predominance of either of the algorithms over the other in their ability to reduce the number of imaging examinations, where both are equally effective. Nor was there any such superiority in the positive predictive value of either of them, a value that was considered low, both lacking methods to increase their specificity. The assessment of the resident physicians who use the algorithms in the emergency service demonstrated statistically significant superiority of NEXUS in terms of both degree of confidence and applicability. CCR is more complex to execute and a has a higher number of lower-precision variables, while NEXUS lacks data about the trauma mechanism and patient age, which would increase its safety, even though it is easier to execute. The study also demonstrated the physicians' preference for NEXUS in daily practice.

Among the limitations of this study, which made it impossible to better elucidate how these tools are used in emergency scenarios in Brazil, with their epidemiological specifics, is the technological inability to calculate the sensitivity and predictive negative value of the algorithms, which would only be possible by submitting all research patients to image study. In addition, another disadvantage was not to have observed each variable of the algorithms individually in order to better characterize them.

Finally, the study corroborates the data in the literature indicating that both algorithms are equally safe for clinical screening of cervical trauma, each of them having its own peculiarities that may influence the personal choice of a physician to use it or not.

All authors declare no potential conflict of interest related to this article. 
CONTRIBUTION OF THE AUTHORS: Each author made significant individual contribution to this manuscript. FL: writing, statistical analysis, intellectual concept and preparation of the entire research project; GFCG: writing, review and supervision of care; OSTP: writing, review and supervision of care; JMSR: preparation of the research project, writing, review and general supervision.

\section{REFERENCES}

1. American College of Surgeons. Advanced Trauma Life Support. $10^{a}$ ed. Chicago, IL: American College of Surgeons; 2018.

2. Burney RE, Maio RF, Maynard F, Karunas R. Incidence, characteristics, and outcome of spinal cord injury at trauma centers in North America. Arch Surg. 1993;128(5):596-9. doi: 10.1001/archsurg.1993.01420170132021.

3. Oliver M, Inaba K, Tang A, Branco BC. Barmparas G, Schnuriger B, et al. The changing epidemiology of spinal trauma: a 13-year review from a Level I trauma centre. Injury. 2012;43(8):1296-300. doi: 10.1016/j.injury.2012.04.021.

4. Moeri M, Rothenfluh DA, Laux CJ, Dominguez DE. Cervical spine clearance after blunt trauma: current state of the art. EFORT Open Rev. 2020;5(4):253-9. doi: 10.1302/20585241.5.190047.

5. Goergen SK, Fong C, Dalziel K, Fennessy G. Can an evidence-based guideline reduce unnecessary imaging of road trauma patients with cervical spine injury in the emergency department? Australas Radiol. 2006;50(6):563-9. doi: 10.1111/j.1440-1673.2006.01655.x.

6. Chaudry J, Swaminathan N, Gershon RK, Gordy DP, Allred L, Lirette ST, et al. Evaluation of clinical criteria to determine the need for cervical spine imaging in victims of blunt assault. J Clin Neurosci. 2020;71:84-8. doi: 10.1016/j.jocn.2019.10.011.

7. Laupacis A, Sekar N, Stiell I. Clinical prediction rules: a review and suggested modifications of methodological Standards. JAMA. 1997; 277(6):488-94.

8. Panacek EA, Mower WR, Holmes JF, Hoffman JR, NEXUS Group. Test performance of the individual NEXUS low-risk clinical screening criteria for cervical spine injury. Ann Emerg Med. 2001:38(1):22-5. doi: 10.1067/mem.2001.116499.

9. Stiell IG, Wells GA Vandemheen KL, Clement CM, Lesiuk H, De Maio VJ, et al. The Canadian C-spine rule for radiography in alert and stable trauma patients. JAMA. 2001;286(15):18418. doi: 10.1001/jama.286.15.1841

10. Hoffman JR, Mower WR, Wolfson AB, Todd KH, Zucker MI. Validity of a Set of Clinical Criteria to Rule Out Injury to the Cervical Spine in Patients with Blunt Trauma. National Emergency X-Radiography Utilization Study Group. N Engl J Med. 2000;343(2):94-9. doi: 10.1056/ NEJM200007133430203

11. Stiell IG, Clement CM, Grimshaw J, Brison RJ, Rowe BH, Schull MJ, et al. Implementation of the Canadian C-Spine Rule: prospective 12 centre cluster randomised trial. BMJ. 2009;339:b4146. doi:10.1136/bmj.b4146.

12. Stiell IG, Clement CM, McKnight RD, Brison R, Schull MJ, Rowe BH, et al. The Canadian C-Spine Rule versus the NEXUS Low-Risk Criteria in Patients with Trauma. N Engl J Med. 2003;349(26):2510-8. doi: 10.1056/NEJMoa031375

13. McGinn TG, GG Wyer, Naylor CD, Stiell IG, Richardson WS. Users' guides to the medica literature. XXII: How to use articles about clinical decision rules. JAMA. 2000:284(1):79-84 doi: 10.1001/jama.284.1.79.

14. Bardin L. Análise do Conteúdo. Lisboa: Almedina; 2002.
15. Ala A, Vahdati SS, Ghaffarzad A, Mousavi H, Mirza-Aghazadeh-Attari M. National emergency $X$-radiography utilization study guidelines versus Canadian C-Spine guidelines on trauma patients, a prospective analytical study. PLoS One. 2018;13(11):1-10. doi: 10.1371/journal.pone.0206283.

16. Kerr D, Bradshaw L, Kelly AM. Implementation of the Canadian C-spine rule reduces cervical spine $x$-ray rate for alert patients with potential neck injury. J Emerg Med. 2005;28(2):12731. doi: 10.1016/j.jemermed.2004.08.016.

17. Griffith B, Bolton C, Goyal N. Screening Cervical Spine CT in a Level I Trauma Center: Overutilization? AJR Am J Roengenol. 2011;197(2):463-7. doi: 10.2214/AJR.10.5731.

18. Dearden C, Hughes D. Does the National Emergency X-ray Utilization Study make a difference? Eur J Emerg Med. 2005;12(6):278-81. doi: 10.1097/00063110-200512000-00006.

19. Duane TM, Wilson SP, Mayglothling J, Wolfe LG, Aboutanos MB, Whelan JF, et al. Canadian Cervical Spine rule compared with computed tomography: a prospective analysis. J Trauma. 2011;71(2):352-7. doi: 10.1097/TA.0b013e318220a98c.

20. Duane TM, Young A, Mayglothling J, Wilson SP, Weber WF, Wolfe LG, et al. CT for all or selective approach? Who really needs a cervical spine CT after blunt trauma. J Trauma Acute Care Surg. 2013;74(4):1098-101. doi: 10.1097/TA.0b013e31827e2acc.

21. Hamaker H. Repeatability and Reproducibility: Some Problems in Applied Statistics, In: Mallows C (Ed.) Design, Data and Analysis, New York: John Wiley; 1987. p. 71-92.

22. Mahadevan S, Mower WR, Hoffman JR, Peeples N, Goldberg W, Sonner R. Interrater reliability of cervical spine injury criteria in patients with blunt trauma. Ann Emerg Med. 1998;31(2):197-201. doi: 10.1016/s0196-0644(98)70306-3

23. Coffey F, Hewitt S, Stiell I, Howarth N, Miller P, Clement C, et al. Validation of the Canadian c-spine rule in the UK emergency department setting. Emerg Med J. 2011;28(10):873-6. doi: 10.1136/emj.2009.089508. Epub 2010 Nov 10.

24. Ngatchou W, Beirnaert J, Lemogoum D, Bouland C, Youatou P, Ramadan AS, et al. Application of the Canadian C-Spine rule and nexus low criteria and results of cervical spine radiography in emergency condition. Pan Afr Med J. 2018;30:157. doi: 10.11604/pamj.2018.30.157.13256.

25. Stiell IG, Clement CM, O'Connor A, Davies B, Leclair C, Sheehan P, et al. Multicentre prospective validation of use of the Canadian $C$-Spine Rule by triage nurses in the emergency department. Cmaj. 2010;182(11):1173-9. doi: 10.1503/cmaj.091430.

26. Stiell IG, Clement CM, Lowe M, Sheehan C, Miller J, Armstrong S, et al. A Multicenter Program to Implement the Canadian C-Spine Rule by Emergency Department Triage Nurses. Ann Emerg Med. 2018;72(4):333-41. doi: 10.1016/j.annemergmed.2018.03.033.

27. Weiner S. The Actual Application of the NEXUS and Canadian C-Spine Rules by Emergency Physicians. Internat J Emerg Med. 2012;5(2):1-5 